\title{
Article
}

\section{Anger expression and suppression at work: causes, characteristics and predictors}

Booth, Jill, Ireland, Jane Louise, Mann, Sandi, Eslea, Mike J and Holyoak, Lynda

Available at http://clok.uclan.ac.uk/15900/

Booth, Jill, Ireland, Jane Louise ORCID: 0000-0002-5117-5930, Mann, Sandi ORCID: 0000-0002-5005-1055, Eslea, Mike J ORCID: 0000-0003-1273-0302 and Holyoak, Lynda ORCID: 0000-0002-4694-5128 (2017) Anger expression and suppression at work: causes, characteristics and predictors. International Journal of Conflict Management, 28 (3). pp. 368-382. ISSN 1044-4068

It is advisable to refer to the publisher's version if you intend to cite from the work. http://dx.doi.org/10.1108/IJCMA-06-2016-0044

For more information about UCLan's research in this area go to http://www.uclan.ac.uk/researchgroups/ and search for < name of research Group>.

For information about Research generally at UCLan please go to http://www.uclan.ac.uk/research/

All outputs in CLoK are protected by Intellectual Property Rights law, including Copyright law. Copyright, IPR and Moral Rights for the works on this site are retained by the individual authors and/or other copyright owners. Terms and conditions for use of this material are defined in the policies page.

\section{CLoK}

Central Lancashire online Knowledge www.clok.uclan.ac.uk

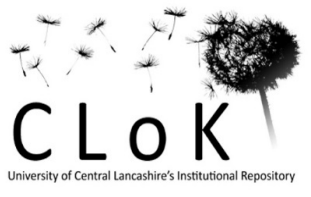




\section{RUNNING HEAD: ANGER AT WORK}

Anger expression and suppression at work: Causes, characteristics and predictors

Jill Booth, Jane L. Ireland ${ }^{1 *}$, Sandi Mann, Mike Eslea, Lynda Holyoak

University of Central Lancashire, Preston, UK; *and Ashworth Research Centre, Mersey Care NHS Trust: UK. 


\section{Abstract}

Purpose: The current study aims to explore the causes, characteristics and consequences of workplace anger expression and suppression, with an additional aim of testing the emotional dimension of Affective Events Theory.

Design/methodology/approach: Participants $(n=187)$ from management and non-management positions completed an event-contingent anger diary over a period of four working weeks, alongside measures on trait anger and job satisfaction.

Findings: Over fifty per cent of the sample disclosed anger causing events. In keeping with Affective Events Theory disposition was important, with trait anger higher in those disclosing anger causing events. There appeared a range of factors predicting the expression of anger, with these focused primarily on individual issues and pre-existing emotion rather than work characteristics.

Originality/value: Through consideration of management and non-management workers and by using a longitudinal design, the study highlights the importance of individual factors in understanding workplace anger. It notes the value in focusing on discrete emotion. The findings offers clear direction for future research that could assist with enhancing models of workplace emotion, particularly if the aim is to account for discrete emotions.

Key Words: Workplace Anger; Affective Events Theory; Emotional Labour; Event-Contingent Method. 
Anger expression and suppression in the workplace: Causes, characteristics and predictors

The importance of emotions in the workplace has been highlighted for many years, dating back to the concept of emotional labour (Hochschild, 1983). This referred to workers having to control their emotions in front of others and actively present a positive emotion when this may not fit with their internal experience (Ashkanasy et al. 2002; Grandey et al. 2002; Tschan, Rochat \& Zapf, 2005; Gabriel, Daniels, Diefendorff \& Greguras, 2015). Both the expression and suppression of emotions within this context is valuable to explore. Despite academic interest in emotions at work (e.g. Ashkanasy et al. 2002; Hulsheger, Lang, Schewe \& Zijlstr, 2015), empirical study has been limited by a tendency for emotion to be discussed in global terms, failing to account either for discrete or negative emotions (Glomb \& Hulin, 1997; Grandey et al. 2002; Ziegler et al. 2012).

Anger as a discrete negative emotion has been neglected in empirical study in the workplace and yet formed one of the original components of the broader concept of emotional labour. It is recognised as a commonly experienced emotion (Fitness, 2000; Moura, Troth \& Jordan, 2015) and associated with a range of outcomes including aggression, stress, poor health and social isolation (Williams \& Williams, 1998; Dahlen \& Deffenbacher, 2001; Mostofsky, Penner \& Mittleman, 2014). However, it is not just the expression of anger that causes difficulties but also its suppression. This has been found to have detrimental effects on health, potentially leading to difficulties such as depression, stress, heart disease, high blood pressure and back pain (Deffenbacher, Oetting, Lynch \& Morris, 1996; Robins \& Novaco, 2000; Burns, Quartana \& Bruehl, 2011).

The experience of anger at work is not unexpected considering how the workplace has been identified as an interpersonally frustrating context (e.g. Fitness, 2000; Grandey et al. 2002; Glaso, Vie, Holmdal \& Einarsen, 2010; Albert \& Moskowitz, 2013). The frequent experiencing of anger in the workplace has been noted, with Gibson \& Barsade (1999), for example, reporting that almost half of all workers felt 'a little angry' at work and almost a quarter felt chronically angry. In a later study Grandey et al. (2002) found that over a two-week period participants experienced 42 per cent 'higher 
anger' events, that is, intense anger causing events. This highlights how anger may not only be experienced frequently at work but that when experienced it is potentially long lasting and intensely felt. Researchers have further noted that workers present with limited strategies in terms of how to deal with this emotion (Moura, Troth \& Jordan, 2015). The frequency of anger incidents has also been found to influence behaviour and attitudes and not necessarily the strength of angry feelings (Ashkanasy et al. 2002; Fisher, 2002; Grandey, Tam \& Brauburger, 2002).

A range of events are identified as likely to promote workplace anger. For example, Fitness (2000) identified the main causes of anger to be unjust treatment, others acting in a morally reprehensible way, others' job incompetence, arrogance or disrespectfulness and being humiliated. Moura, Troth \& Jordan (2015) reported similar findings, noting the main causes of anger to be unfair treatment, workplace incompetence, disregard by others and concern for 'the bottom line'. In addition, a diary study carried out by Grandey et al. (2002) reported 'personal attack', others' incivility, someone interfering with a worker's work related goal and issues regarding policy/structure difficulties as causes of worker anger. Thus, there is support in the literature that the causes of workplace anger are far-ranging and an employee's perception of events, their view of the organisation, and their perception of co-workers are particularly important elements to consider.

Nevertheless, anger has not avoided criticism concerning its definition. Berkowitz (1999) describes it as an experience of feeling, internal bodily reactions, and an attitude toward others that leads to the potential for aggression, whereas Dahlen and Daffenbacher (2001) describe it as an internally experienced state that includes four related domains; emotion, physiological arousal, cognitive processes, and behaviour that can be either functional or dysfunctional and not necessarily include an act of aggression. Despite some differences in definition there is general consensus that anger comprises state (i.e. dynamic, current) and trait (i.e. more enduring) elements and is a multifaceted concept that it can have damaging properties to those experiencing it, suppressing it and/or exposed to it. Equally, there is recognition that it can have positive outcomes, particularly in terms of communicating intention and distress and in aiding motivation (Averill, 1982; Fitness, 2000). 
Consequently, examining anger as a discrete emotion becomes important on the grounds that is it frequently occurring, associated with a range of adaptive and maladaptive outcomes, and underpinned by a number of factors. Furthering an area of study does not, however, mean that the mere identification of anger as an important emotion within the workplace is sufficient; rather there is a need to identify the specific factors associated with becoming angry at work so that a formulation can be developed that can then support the outline of a theoretical model. A notable omission from the literature has been the failure to propose a theory of workplace anger expression and suppression, particularly one that involves the dynamic process of anger incidents at work and how they unfold.

Comprehensive models outlining emotions and outcomes are certainly evidenced within the broader field of study, such as aggression (e.g. Huesmann, 1998; Integrated Information Processing Model; Anderson \& Bushman, 2002; DeWall, Anderson, \& Bushman, 2011; General Aggression Model) where attention is afforded to the dynamic elements of triggers and outcomes. These models further capture how events (i.e. a trigger, such as anger) lead to a process of emotional and cognitive interpretation affected by prior experiences, dispositional characteristics, learning and current emotional context. Thus, process models that can account for a dynamic variable, such as emotion, are certainly not absent from the wider field. Nevertheless, models that focus on single discrete emotions (e.g. anger) and their application to a specific environment (i.e. the workplace) have not been uniquely considered. The workplace environment is worthy of such attention owing to the need to suppress the expression of negative emotion, thereby requiring emotional labour (Hoschild, 1983; Tschan, Rochat \& Zapf, 2005).

One potentially valuable theory to consider that is able to capture emotions in real time is Affective Events Theory (AET; Weiss \& Cropanzano, 1996). AET is concerned with the way an employee feels while working (Cropanzano \& Dasborough, 2015) and has had application to understanding how negative events can impact on emotion (Glaso, Vie, Holmdal \& Einarsen 2010). AET specifically allows emotions to be measured as they are experienced and allows for information, such as the frequency of emotions, to be aggregated across time (Fitness, 2000). AET focuses on the 
structure, causes and consequences of affective experiences at work, examining the antecedents of employees' experiences of work events and the affective, attitudinal and behavioural reactions to these events. It is essentially concerned with the way people feel while working and includes both mood and emotions under the rubric of affective work events (Fisher, 2002).

Fisher (2002) provides an example of how AET relates to experiencing mood and emotions at work. First, stable work environment features, such as job and role characteristics, operate by influencing the more or less frequent occurrence of real-time work events, and these discrete events are the causes of momentary positive or negative moods and emotions (affective reactions). In turn, cumulative experiences of momentary positive and negative feelings while working influences work attitudes. Work environment features may then affect work attitudes directly through judgement driven processes as well as indirectly through their effect on work events and affective reactions. Second, AET also suggests that dispositional affectivity influences momentary or state affect and that the impact of affective disposition on work attitudes is largely mediated through affective state affect. Finally, AET proposes that some behaviour is directly driven by impulsive feelings (affective-driven behaviour) rather than by work attitudes. Other types of behaviour (judgement/cognitive-driven behaviour), may be a consequence of more carefully considered judgements, which are believed to be informed by relatively stable attitudes, such as measures of job satisfaction.

Importantly, AET has argued for both negative and positive emotion to be included (Carlson et al. 2011), essentially describing how work events can lead to an affective reaction that can influence attitudes towards work and produce a behavioural reaction based on a judgement of what has taken place. Likely underpinning employee reactions is the affective disposition that an individual has and the specific characteristics of the work environment. Thus, AET represents a multi-faceted model that accounts for both dynamic and dispositional factors, recognising the impact of affect on attitudes and behaviour, and how the work environment influences this.

Support for AET has been found. For example, Fisher (2002) employed Event Sampling Methodology over a two week period and found that perceived job characteristics such as, task 
identity, skill variety, task significance, autonomy and feedback predicted positive affective reactions while role conflict predicted negative affective reactions. Dispositional positive affectivity also predicted positive affective reactions. In addition, Glaso, Vie, Holmdal \& Einarsen (2010) found that emotional experiences partly acted as a potential mediator between exposure to negative events at work (i.e. bullying) and job satisfaction and intention to leave; specifically they noted that trait anxiety (and not trait anger) moderated the relationship between exposure to the negative event and their emotional experiences.

Ashkanasy et al. (2002) argues that AET is important in highlighting how emotions in organisations and the events that cause them are not to be ignored, even if they appear relatively minor. The sorts of events that generate negative emotions not only include interactions with customers and those external to the organisation, but also interactions with supervisors, co-workers, and subordinates (i.e. those internal to the organisation). These events can be cumulative. Furthermore, Ashkanasy et al. (2002) claim that it is not the intensity of these events that leads to affective states but more the frequency with which they occur; workers may be capable of dealing with infrequent occurrences, even when these are relatively intense, but if the negative events are unremitting this will raise the risk for a [negative] affective state.

Nevertheless, AET is limited by the fact that it represents a global model of emotional expression and does not capture discrete emotions, such as anger. It omits how anger is experienced as a process across time and does not account for the more dynamic components of cognition. These are significant omissions, particularly when it is agreed that anger forms part of a process, with cognition an important component relating to both its expression and suppression (Berkowitz, 1999; Dahlen and Daffenbacher, 2001).

There is consequently a need to consider empirically how anger as a discrete emotion is experienced in the workplace. Exploring this across the employment sector to obtain a broad sample of experiences and utilising methods that can capture state anger is equally required. The current research aims to add to the literature base by examining these areas in management and non- 
management workers from across the employment sector. It aims to examine the factors that associate with work-based anger and test components of the AET model. Importantly, the current study is only focused on the emotional dimensions of AET and does not extend beyond this.

The following represent the core hypotheses that will be tested by the current study: 1.) That at least half the sample will report incidents prompting feelings of anger (e.g. Gibson \& Barsade, 1999); 2.) The main causes of anger will represent a perception of unfair treatment, workplace incompetence and disrespectful behaviour by others (e.g. Moura, Troth \& Jordan, 2015; Fitness, 2000); 3.) In keeping with the Affective Events Theory it is expected that those with an increased relevant affective dispositional component (e.g. trait anger) will be more likely to report anger incidents and express their anger than those without (Cropanzano \& Dasborough, 2015); and 4.) Perceived work characteristics, such as role conflict, will predict anger expression (Fisher, 2002).

\section{Method}

\section{Participants}

Two hundred and sixty four participants in full time employment were invited to take part in the study. A quota sample was recruited whereby equal numbers of participants were chosen from each of the four sectors: retail, wholesale, education and health. In addition, half of the participants in each sector held managerial positions and half held non-managerial positions. Participants were given the opportunity to take part in a free draw to win $£ 200$ in cash for taking part in the study. In total, 187 participants took part (71\% response rate). Thirty-three per cent were from the retail sector, $28 \%$ wholesale, $19 \%$ education, and $20 \%$ health. Fifty two per cent were in a managerial/supervisory position. Fifty-four per cent of the sample were women, with sex approximately equal across position and sectors, apart from wholesale (36\% women) and health ( $87 \%$ women).

Measures

Experience Sampling Methodology (ESM) was employed. This involves the in-depth study of everyday experiences and on-going behaviour in the natural environment to assist with improved ecological validity and reduce the biases connected with retrospective recall. Participants completed 
brief diaries that were event contingent as opposed to signal or interval, allowing them to report on an angry event each time it occurred (i.e. an event that caused them to experience anger). The diary format was developed with attention to an earlier study (Booth \& Mann, 2005) that conducted 24 semi-structured interviews with those in management and non-management positions. These interviews included open-ended questions about participants' personal experiences of anger at work. These findings were combined with previous research (e.g. Fitness, 2000) and the AET model to produce the diary format and content. Participants completed the diary over a four-week (20 working days) period.

The diary comprised eight sections $(\mathrm{A}-\mathrm{H})$, which covered each component of the theoretical model; A. Frequency, context and source; B. Causes of anger; C. Influences of anger; D. Intensity and duration; E. Expression, suppression and control of anger; Suppression referred to keeping their anger in and not letting others know they were angry, with anger control referring to the extent to which they felt in full control of their anger during the incident and were attempting to monitor or prevent the expression of angry feelings; F. Faking emotion; G. Short-term consequences of anger incidents; and H. Job satisfaction. Response formats were varied within each section in order to maintain participant interest and to prevent habituation to completion. Participants also completed the following.

State Trait Anger Expression Inventory (STAXI-2; Spielberger, 1999): The STAXI-2 is widely used to assess the extent to which individuals' experience, express and control their anger. It comprises 57 items covering overall trait and state aggression, measured on a four point Likert scale from 1 (almost never) to 4 (almost always). The current study focused on trait anger.

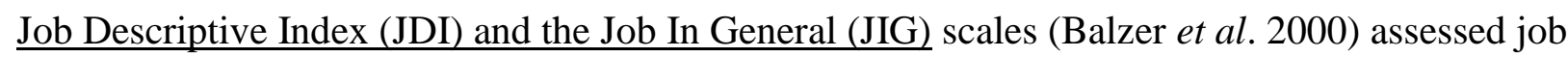
satisfaction. The JDI and JIG are frequently used measures of job satisfaction and comprise 72 items and 18 items respectively. The JDI is made up of five sub-subscales or facets: work itself, pay, opportunities for promotion, supervision, and co-workers (people). The JIG reflects individuals' general feelings toward their employment, encompassing all aspects of job satisfaction. Participants respond by marking yes, no or cannot decide. 
Procedure

Ethical approval was obtained from the university ethics board prior to data collection.

Participant recruitment was conducted with the consent of Human Resources or management. Prior to the main study a pilot of the diary was conducted with eight participants split equally across sectors, sex, and management versus non-management positions. They were invited to complete the diary for a seven-day period. This pilot let to alterations to only three questions within the diary. The research then proceeded to the main study.

All participants were given a unique research code and invited to take part in a lottery to encourage participation and retention. Consequently, all participants were provided with a ticket at the beginning of the study, which was the same as their unique research code. Every participant who completed all parts of the study was included in the lottery. Participants were initially asked to complete the STAXI-2, JDI and JIG questionnaires. Once these were returned to the researcher, participants were given full instructions on how and when to complete the anger diary and an opportunity to raise any questions with the researcher. Participants were advised to complete the diary as soon as possible after they felt the anger incident was over. If the anger incident continued then participants were asked to complete the diary no later than twenty-four hours after the incident began. Participants returned diaries via a pre-paid envelope to the researcher or via a sealed box at their workplace, collected at the end of the diary-keeping period by the researcher.

\section{Results}

Of the 187 participants that responded, 98 provided information regarding their anger diary meaning that a total of 53 per cent filled in at least one record on the anger diary. In total there were 268 anger causing incidents reported from across the sample.

\section{Causes of workplace anger}

Participants were asked to only choose one cause for each incident. The most frequent response was for the category immoral behaviour (18.5\%), with participants most commonly choosing the following responses; they were lazy, rang in sick and you suspected they were lying, they were 
constantly moaning and were misbehaving. Disrespect (15.4\%) was the next most frequent category chosen, with participants primarily choosing the option they were rude to you. This was followed by the category of job incompetence (13.3\%). The final category was unjust treatment $(8.3 \%)$, with participants most frequently choosing the response of being unjustly criticised. Seventy-six per cent of anger causing events related to those internal to the organisation (i.e. did not involve those external, such as customers or suppliers).

\section{Duration of anger}

Just over ten per cent of the sample reported their anger lasted for less than five minutes (12\%), with over a fifth (21\%) reporting that it lasted for 5 to 10 minutes. Eighteen per cent reported their anger lasting less than 30 minutes, $13 \%$ an hour, $13 \%$ one to two hours, $14 \%$ half a day (14\%), and $9 \%$ one day or more.

\section{Expression, suppression and control of anger}

Forty two per cent of the anger incidents reportedly involved the expression of anger, 49 per cent the suppression of anger (i.e. keeping anger in, not accepting it, and not letting others know they were angry) and nine per cent the reported control of anger (i.e. allowing themselves to experience anger and feeling in total control of their anger during the incident; attempting to monitor or prevent the expression of angry feelings). There were no differences across the sectors (i.e. retail, wholesale, education, health) with regards to the frequency of anger expression, suppression or control. Of those expressing their anger, $32 \%$ did so to a superior manager/supervisor, $42 \%$ to a co-worker and $26 \%$ to a subordinate. Of those suppressing their anger, $36 \%$ did so towards a superior manager/supervisor, $43 \%$ towards a co-worker and $21 \%$ towards a subordinate. Anger control was most likely to occur in relation to a co-worker $(61.5 \%)$ followed by superior manager/supervisor $(23 \%)$ and subordinate $(15.5 \%)$

Anger expression behaviours displayed included being verbally abusive (47.5\% of incidents), verbally non-abusive (28\%), communicating expression via body language (21\%), and physical 
aggression (3.5\%). Anger suppression included staying quiet (62\% of incidents) and walking away $(38 \%)$.

Regarding hiding emotions of anger (i.e. faking emotion) from the trigger person (i.e. those they considered to be the cause of their anger), $54 \%$ of those reporting anger incidents indicated they would do this, ranging from 'somewhat' to 'a lot'. Of these, $12.5 \%$ reported to do this 'a lot'. Twenty-nine per cent indicated they would not try and present an alternative emotion that they did not feel. Regarding hiding their anger from others (i.e. beyond the trigger person), $41 \%$ of those reporting anger causing incidents indicated that they would do this, ranging from 'somewhat' to 'a lot'. Of these, $10 \%$ reported to do this 'a lot'. Twenty-eight per cent indicated they would not try and present an alternative emotion that they did not feel.

\section{$\underline{\text { Trait anger and its association with incidents }}$}

Table 1 presents the mean scores for trait anger (STAXI-2) across the sample and for those reporting incidents of anger versus those that did not. This was conducted to determine if trait anger was discriminating between participants. Trait anger was assessed at one time point only, namely at the start of the diary completions.

$<$ Table 1 here>

A univariate ANOVA was completed on the overall Trait Anger score. This demonstrated that those reporting anger causing events had higher levels of overall trait anger that those that did not $(F(1,185)=5.38, p<.02)$. A further univariate ANOVA was completed on the overall Anger Expression Index, which demonstrated no significant differences $(F(1,185=3.27 \mathrm{~ns})$. A MANOVA on the four related subscales (Anger Control Out; Anger Control In; Anger Expression Out; Anger Expression In) indicated no main effect $(F(4,182)=.96 \mathrm{~ns})$.

\section{The anger-provoking incident: Modelling predicting characteristics}

The characteristics associated with the anger-provoking incident was next explored. In fitting the model two tests were conducted; the first examined whether or not the factors and covariates assessed in this study were providing any information (Test of Model Effects) and the second, the 
Parameter Estimates Table, included tests on how significant the levels were within a category, with respect to the reference category. A Logistic General Estimating Equation (G.E.E.) with a Logit Link Function was used to test the distribution of the dichotomous dependent variable expression and suppression of anger.

The model built looked at which attributes of an anger incident influenced expression of anger to the trigger person. The dataset included 268 anger incidents across 98 participants. The model built looked at which attributes of an anger incident influenced expression of anger to a trigger person. Within the anger diary participants could mark whether in a given anger incident they expressed, suppressed or controlled anger. Only 25 incidents involved the control of anger. These incidents were thus dropped from the analysis so that the model could then account not just for whether or not the incident involved expression, but whether the incident involved expression or suppression. To control for those reporting more than one incident of anger and the risk that these could be correlated in some way (and thus resulting in possible dependency in the data set), more sophisticated modelling techniques were employed, namely Generalizing Estimating Equations (GEEs), specifically Population Averaged GEE (PA-GEE) that allows the relationship between the independent variables and the dependent variable to be considered with respect to a population rather than a single individual.

The outcome variable used was expression of anger to the trigger person. This is a binary variable with two possible outcomes: Yes ('I did express my anger') and No ('I did not express my anger'). To accommodate for the binary nature of the dependent variable a Logistic GEE with a Logit Link Function was used. The reference category was set to the first level and all variables were specified as having a main effect.

To proceed with the modelling process, non-significant variables were removed and the model re-run. The criteria for inclusion was consequently set at $p<.05$, with the final model accepted only when the overall model was below .05, allowing for interpretation of the parameter estimates. Table 2 includes the Test of Model Effects indicating the retained variables, namely all of those that were found to be statistically significant in explaining the dependent variable - expressing anger to the 
trigger person. Table 3 includes the parameter estimates for retained variables. All the results are in terms of expression: this means that the higher the $\operatorname{Exp}(\mathrm{B})$ the more likely angry incidents will result in expression of anger and therefore less likely to result in anger suppression ${ }^{1}$.

<Insert Table 2 here>

<Insert Table 3 here>

Discussion

The present study demonstrates the prevalence of anger causing events in the workplace, and the range of causes that can provoke such events. These include those specific to the individual as opposed to the wider workplace context and comprise dispositional factors. The study also confirmed evidence for emotional labour (e.g. Hochschild, 1983; Ashkanasy et al. 2002; Gabriel et al. 2015), particularly in relation to the hiding of emotion from the trigger person, with around half of participants reporting this. The presentation of an alternative emotion was more limited by comparison and reported by approximately one third of participants. Nevertheless, this provided evidence of emotional labour as a reliable concept across employment sectors. The current study suggests more examination is required concerning the individuals who present with this tendency and the processes that are enacted (e.g. cognitive processes) versus those that are not engaging in this process, particularly when accounting for a discrete emotion such as anger. Indeed, the current study highlights the importance of accounting for discrete emotion.

Over half the sample disclosed incidents prompting feelings of anger occurring in the fourweek study period, with this proportion consistent with previous research (Gibson \& Barsade, 1999). It supported the prediction and highlighted the exposure to anger-provoking incidents as not isolated to a small proportion of the workforce. This is consistent with recognition that the workplace is an interpersonally frustrating context (e.g. Fitness, 2000; Albert \& Moskowitz, 2013) and thus anger causing events should not be surprising. The reasons for these anger causing events were also in keeping with expectations from the literature and the noted prediction. For example, disrespectful behaviour was one of the most reported causes, followed by job incompetence and unjust treatment 
(Fitness, 2000; Grandey et al. 2012; Moura et al. 2015), which supported the prediction. However, the most frequently reported cause was that of immoral behaviour by others (e.g. lying, phoning in sick without cause), which has been found in previous research (Fitness, 2000) but not consistently so. It could be possible that such a cause is dependent on wider issues such as pressure on particular work environments and a reduction in work condition quality more broadly. The current study did not capture these aspects and thus cannot comment on them.

One of the most interesting findings related to the potential role for disposition as a factor distinguishing between those reporting exposure to an anger event and those who did not. In accordance with Affective Events Theory it was expected that disposition (i.e. traits) would represent a distinguishing factor (Fitness, 2000), with such disposition raising the potential not only for exposure to anger but more importantly to the perception of exposure to an anger-provoking event. Disposition is certainly a factor accounted for in the wider aggression literature, particularly in models such as the General Aggression Model (Anderson \& Bushman, 2002; Dewall et al. 2011) that argues for dispositional personality (including trait anger) as a risk factor for aggression dependent on the circumstances. The current study found support for this in that anger as a trait (dispositional) variable was higher among those reporting anger causing events, thus in keeping with the prediction. However, the prediction was only partially supported in that although overall trait anger was a distinguishing factor, the actual tendency to express anger was not. This could offer some explanation as to why the supressing of anger was reported by around half the sample; the tendency to experience anger in itself may be insufficient, the tendency to express also needs to be evidenced.

Models such as Affective Events Theory do not, however, offer explanations regarding the suppression of anger and/or what allows an individual to successfully manage their angry emotions. These aspects are though perhaps the most useful in explaining how anger can be managed more successfully at work. In the current study, for example, around half who experienced anger due to an event did not express this and did not always display a behavioural reaction; this would not therefore support a simplistic interpretation of Affective Events Theory where a behavioural reaction is 
expected. Supressing anger by remaining quiet (62\% of incidents), for example, cannot be considered a clear behavioural reaction. This finding would suggest a need for more elaboration on this particular component of the Affective Events Theory.

Connected to this, the specific target of the anger appeared important. The current study demonstrated how many participants exposed to an angry event did not communicate this anger towards a co-worker. It could be speculated that this is a result of having to continue to work effectively with co-workers and to maintain 'relationship harmony' (Thomas, Smucker \& Droppleman, 1998). This was supported by the finding in the current study that increased satisfaction with those you worked with resulted in less likelihood of anger expression. Thus tolerance levels have to increase. Equally, such individuals are perhaps viewed as less justified targets in comparison to those who present either with less (subordinate) or more (supervisor/manager) perceived or actual power and for whom controlling anger towards was less likely in the current study. Subordinates appear particularly at risk, with only 15 per cent of participants reporting that they would control their anger towards such a target. Thus the specific target appears a particular consideration. This is not currently captured in models such as Affective Events Theory.

The key question to then address becomes what the predictors of these anger-provoking events represent. It was predicted that work characteristics (such as role conflict) would represent a main predictor (Fisher, 2002) but this was not found to be the case. Powerlessness was the only associated predictor that arguably had some link to work characteristics, but this was not a particularly large predictor. Instead it appears that predictors were focused more on the individual perceptions that a worker had concerning the causes of anger and their perception of the behaviour of others. This included disrespectful behaviour, unjust treatment by others, unprofessional behaviour, feelings of humiliation/jealously, and perceiving job incompetence in others. General satisfaction with your own work and pre-existing stress were also key predictors in expressing anger, with satisfaction with your work colleagues leading to an increased likelihood of not expressing your anger. Collectively though these predictors argue for a more individualised understanding of workplace anger than that offered by 
models that are trying to combine both the individual and their work environment as core factors. Undoubtedly the work environment will have an influence but it appears to be the individual interpretations of this environment and the perception of the relationships with those within this environment that are driving discrete emotion, in this instance anger.

There are important considerations that generate from this that models of workplace anger need to account for. The first includes more attention to the dispositional elements that could drive affect, extending this beyond trait anger, and the second to the importance of cognition and related aspects such as attribution. Such components are considered driving factors in the expression of behaviour and emotion and are commonly accepted in the aggression literature (Huesmann, 1998; Anderson \& Bushman, 2002; DeWall et al. 2011; Ireland, 2011) but appear to have only received a cursory mention in the workplace literature by comparison. The Affective Events Model, for example, does capture the potential for a cognitive influence but this is cursory and does not extend to those aspects likely to be of considerable significance (e.g. hostile attribution biases; misattribution or misinterpretation; normative beliefs; Huesmann, 1998; Ireland, 2011). In addition, there is more work required to capture how the accumulation of emotions may be important; focusing on one discrete emotion is valuable but the current study demonstrates that feelings of pre-existing stress is an important predictor. Thus it is the potential accumulation of both an anger-provoking event and stress that is important, but this is not currently captured by pre-existing workplace models of emotion.

The current research does not, however, allow for consideration of whether or not dispositional anger is more important to consider for recruitment than workplace stressors. The present findings indicate that dispositional issues are an important consideration although so is the tendency to express or supress anger; a dispositional tendency towards experiencing anger, as noted earlier, may not be enough, it may be the susceptibility to express or deal inappropriately with this anger that is important. It is not the experiencing of anger therefore but its' management, with this arguably influenced by environmental factors such as the presence of others inhibiting anger expression as supported by the concept of emotional labour (e.g. Hochschild, 1983; Tschan et al. 2005; Gabriel et al. 2015). The 
relative contribution of disposition and environment is not, however, an area the current research can directly address but it does point to the value of future research capturing these factors in more detail.

The current study is not without its limitations. Acknowledging experiences of anger do require insight and a willingness to report what can be a stigmatised emotion. A degree of underreporting of experiences is not therefore unexpected. It is further recognised that the method of sampling may have only included those participants who felt able to complete the diary and considered they had sufficient time to do so. A recognised challenge with diaries is participant forgetfulness. Despite an instruction to fill out the diary sheets regularly and promptly participants do not always do this and data can be lost. In addition, asking participants to record anger incidents no later then 24 hours after the incident initially runs the risk that data on anger incidents that lasted longer than this may not have been captured. However, the researcher had to ensure that memory biases were limited and asking participants to record incidents beyond this time frame may have resulted in participants forgetting important information about the incident, or forgetting to complete an entry. Conversely, the instructions to attend to interactions so that they may later be recalled may make participants unduly self-conscious and aware of their behaviour so that it comes disrupted or subject to strain (Ashkanasy et al. 2002). This is referred to as 'reactance' and it is possible that participants became more aware of the behaviour and either became angrier or less angry over the diary keeping period as a result.

Nevertheless, the research offers some further insights into workplace emotions. By adopting a longitudinal design and focusing on a discrete emotion (anger) it has been able to isolate the specific causes and predictors of this. It highlights the prevalence of anger in the work environment and the role that the individual may play in the interpretation and experiencing of such events. Evidence was found for the concept of emotional labour, for disposition as a variable of interest, for the importance of the accumulation of emotions, and for how the potential target of anger can determine its expression. Support is offered for some aspects of Affective Events Theory but also a criticism of its failure to account for the individual context in more detail, particularly in relation to cognition, 
interpersonal relationships, and the accumulation of emotion. All of these are suggested by the current study to be worthy of future research. Such research could also capture the contribution of the interaction between those involved in angry incidents to determine how incidents escalate and dissipate as a product of interaction; what the current research focuses on are the perceptions of the individual recording their experience of anger and not the interplay between them and the trigger for their anger. Connected to this, future research would also benefit from capturing data relating to the positive expression of anger as a motivating emotion and the circumstances in which this can be expressed or supressed, along with detail on justifications for anger expression and the actual or perceived benefits of this to those expressing anger (e.g. Averill, 1982; Fitness, 2000; Van Doorn, van Kleef \& van der Pligt, 2015; Van Kleef, van den Berg \& Heerdink, 2015).

\section{References}

Albert, L. S. and Moskowitz, D. S., 2013. Quarrelsomeness in the workplace: An exploration of the interpersonal construct within the organizational context. Organizational Psychology Review, $4(1)$, pp. $27-48$.

Anderson, C. A. and Bushman, B. J.. 2002. Human aggression. Psychology, 53(1), pp. 27 - 51.

Ashkanasy, N. M., Hartel, C. E. J. and Daus, C. S., 2002. Diversity and emotion: The new frontiers in organizational behaviour research. Journal of Management, 28(3), pp. 307 - 338.

Averill, J. R., 1982. Anger and aggression: An essay on emotion. Springer-Verlag: New York, NY.

Balzer, W. K., Kihm, J. A., Smith, P. C., Irwin, J. L., Bachiochi, P. D., Robie, C., Sinar, E. F. and Parra, L. F., 2000. Users' manual for the Job Description Index and the Job in General scales. In J. M. Stanton. and C. D. Crossley., eds., Electronic resources for the JDI and JIG. Bowling Green, OH: Bowling Green State University.

Berkowitz, L., 1999. Anger. In T. Daldleish. and M. Power., eds., Handbook of cognition and emotion. England: John Wiley \& Sons Ltd.

Booth, J. and Mann, S., 2005. The experience of workplace anger. Leadership \& Organization Development Journal, 26(4), pp. 250-262. 
Burns, J.W., Evon, D. and Strain-Saloum, C., 1999. Repressed anger and patterns of cardiovascular self-Report and behavioural Responses: Effects and harassment. Journal of Psychosomatic Research, 47(6), pp. 569-581.

Burns, J. W., Quartana, P. and Bruehl, S., 2011. Anger suppression and subsequent pain behaviours among chronic low back pain patients: Moderating effects of anger regulation style. Annals of Behavioural Medicine, 42(1), pp. 42 - 54.

Carlson, D., Kacmar K. N., Zivnuska, S., Ferguson, M. and Whitten, D., 2011. Work-family enrichment and job performance: A constructive replication of affective events theory. Journal of Occupational Health Psychology, 68(3), pp. 297 - 312.

Cropanzano, R. and Dasborough, M. T., 2015. Dynamic models of well-being: Implications of affective events theory for expanding current views on personality and climate. European Journal of Work and Organisational Psychology. pp. 1 - 4.

Dahlen, E. R. and Deffenbacher, J. L., 2001. Anger management. In J. W. Lyddon., ed., Empirically supported cognitive therapies: Current and future applications. New York: Springer Publishing.

Deffenbacher, J. L., Oetting, E. R., Lynch, R.S. and Morris, C. D., 1996. The expression of anger and its consequence. Behaviour Research Therapy, 34(7), pp. 575-590.

DeWall, C. N., Anderson., C. A. and Bushman, B. J., 2011. The general aggression model: theoretical extensions to violence. Psychology of Violence, 1(3), pp. 245.

Fisher, C. D., 2002. Antecedents and consequences of real-time affective reactions at work. Motivation and Emotion, 26(1), pp. 3-29.

Fitness, J., 2000. Anger in the workplace: an emotional script approach to anger episodes between workers and their superiors, co-workers and subordinates. Journal of Organisational Behaviour, 21(2), pp. 147-162.

Gabriel, A. S., Daniels, M. A., Diefndorff, J. M. and Greguras, G. J., 2015. Emotional labour actors: A latent profile analysis of emotional labor strategies. Journal of Applied Psychology, 100(3), pp. $863-879$. 
Glaso, L., Vie, T. L., Holmdal. G. R. and Einarsen, S., 2010. An application of Affective Events Theory to workplace bullying. European Psychologist, 16(3), pp. 198 - 208.

Gibson, D. E. and Barsade, S. G. 1999. The Experience of anger at work: Lessons from the chronically angry. Paper presented at the Academy of Management, Chicago, IL, August $11^{\text {th }}$.

Glomb, T. M. and Hulin, C. L.,1997. Anger and gender effects in observed supervisor-subordinate dyadic interactions. Organisational Behaviour and Human Decision Processes, 72(3), pp. 281307.

Grandey, A. A., Tam, A. P. and Brauburger, A. L., 2002. Affective states and traits in the workplace: Diary and survey data from young workers. Motivation and Emotion, 26(1), pp. 31-55.

Hochschild, A.R., 1983. The managed heart. Berkeley, CA and Los Angeles, CA: University of California Press.

Huesmann, L. R., 1998. The role of social information processing and cognitive schema in the acquisition and maintenance of habitual aggressive behaviour. In R. G. Geen. and E. Donnerstein., eds., Human aggression: Theories, research and implications for social policy (pp. 73- 109). London: Academic Press Ltd.

Hulsheger, U. R., Lang, J. W. B., Schewe, A. F. and Zijlstr, F. R. H., (2015). When regulating emotions at work pays off: A diary and intervention study on emotion regulation and customer tips in service jobs. Journal of Applied Psychology, 100(2), pp. 263 - 277.

Ireland, J. L., 2011.Violence assessment and intervention. In G. Davey., ed., Introduction to applied psychology. London, England: BPS Wiley-Blackwell.

Mostofsky, E., Penner, E. A. and Mittleman, M. A., 2014. Outbursts of anger as a trigger of acute cardiovascular events: A systematic review and meta-analysis. European Heart Journal, 35(21), pp. $1404-1410$.

Moura, K., Troth, A. C. and Jordan, P. J., 2015. Crossing the impropriety threshold: A study of experiences of excessive anger. New Ways of Studying Emotions in Organisations, 11, pp. $369-$ 395. 
Robins, S. and Novaco., R.W., 2000. Anger control as a health promotion mechanism. In D.

Mostofsky. and D. Barlow., eds., The management of stress and anxiety in medical disorders. Boston, US: Ally \& Bacon.

Spielberger, C. D., 1999. State-Trait Anger Expression Inventory - 2. Professional manual. Odessa, Florida, US: Psychological Assessment Resources.

Thomas, S., Smucker, C. and Droppleman, P., 1998. It hurts most around the heart: a phenomenological exploration of women's anger. Journal of Advanced Nursing, 28(2), pp. 311322.

Tschan, F., Rochat, S. and Zapf, D., 2005. It's not only clients: Studying emotion work with clients and co-workers with an event-sampling approach. Journal of Occupational and Organizational Psychology, 78(2), pp. 195-220.

Van Doorn, E. A., van Kleef, G. A. and van der Pligt, J., 2015. How emotional expressions shape prosocial behavior: Interpersonal effects of anger and disappointment on compliance with requests. Motivation and Emotion, 39(1), pp. 128-141.

Van Kleef, G. A., van den Berg, H. and Heerdink, M. W., 2015. The persuasive power of emotions: Effects of emotional expressions on attitude formation and change. Journal of Applied Psychology, 100(4), pp. 1124.

Weiss, H. M. and Cropanzano, R., 1996. An affective events approach to job satisfaction. In B. M. Staw. and L. L. Cummings., eds., Research in organizational behavior (pp. 1 - 74), Vol 18. Greenwich, CT: JAI Press.

Williams, R. and Williams, V., 1998. Anger kills. London: Times Books, Random House.

Ziegler, R., Schlett, C., Casel, K. and Diehl, M., 2012. The role of job satisfaction, job ambivalence, and emotions at work in predicting organizational citizenship behavior. Journal of Personnel Psychology, 11, pp. $176-190$. 


\section{Footnote}

${ }^{1}$ The model looks at the odds of expressing relative to suppressing of a given category to its baseline reference category). For instance, if the $\operatorname{Exp}(\mathrm{B})$ (i.e. the relative odds) value is 2 for category A this means that the odds for expressing (relative to suppressing) are twice that of the odds of expressing in the baseline category. So in short, those in category A are more likely to express than those in the baseline. If the $\operatorname{Exp}(\mathrm{B})$ value is 0.5 for category B, then we can say the odds of expressing (relative to suppressing) are 0.5. times that of the odds of expressing in the baseline category. So we can say the odds of expressing (relative to suppressing) are half that of the odds of expressing in the baseline category. In short, those in category B are less likely to express than those in the baseline. Since the only other option to express is suppress, we can say that those in category B are more likely to suppress than those in the baseline. 
Table 1

Trait anger between those reporting anger causing events and those with no events

\begin{tabular}{lll}
\hline STAXI-2 Scale & Those reporting an anger event & \multicolumn{1}{c}{ Those not reporting an anger } \\
& $(\mathbf{n}=\mathbf{9 8})$ & event $(\mathbf{n}=\mathbf{8 9})$ \\
& & \\
& Mean/SD & Mean/SD \\
\hline Overall Trait Anger & $18.7 / 4.4$ & $17.3 / 4.3$ \\
\hline Anger Expression Out & $14.4 / 3.5$ & $13.6 / 3.7$ \\
Anger Expression In & $17.1 / 4.4$ & $16.3 / 4.11$ \\
Anger Control Out & $23.6 / 6.5$ & $24.6 / 5.5$ \\
Anger Control In & $22.0 / 4.9$ & $23.3 / 5.6$ \\
\hline Anger Expression Index & $33.9 / 13.1$ & $30.3 / 14.4$ \\
\hline
\end{tabular}


Table 2

Test of model effects with main variables: Significant predictors of expressing anger to the trigger person

\begin{tabular}{lll}
\hline Variable & Wald $\chi^{2}$ & $\mathbf{d f} / \boldsymbol{p}$ \\
\hline Employment sector & 17.6 & $3 / .001$ \\
Relationship with trigger & 15.4 & $6 / .02$ \\
person & & \\
Cause of anger & 21.3 & $11 / .03$ \\
Already stressed & 7.89 & $1 / .005$ \\
JDI work & 6.42 & $1 / .01$ \\
JDI people & 15.2 & $1 / .001$ \\
\hline
\end{tabular}

Goodness of fit for model: $\quad$ QIC: 308.4; QICC: 305.5 
Table 3

Parameter estimates across retained main variables, presented in rank order of Exp(B) for each main variable.

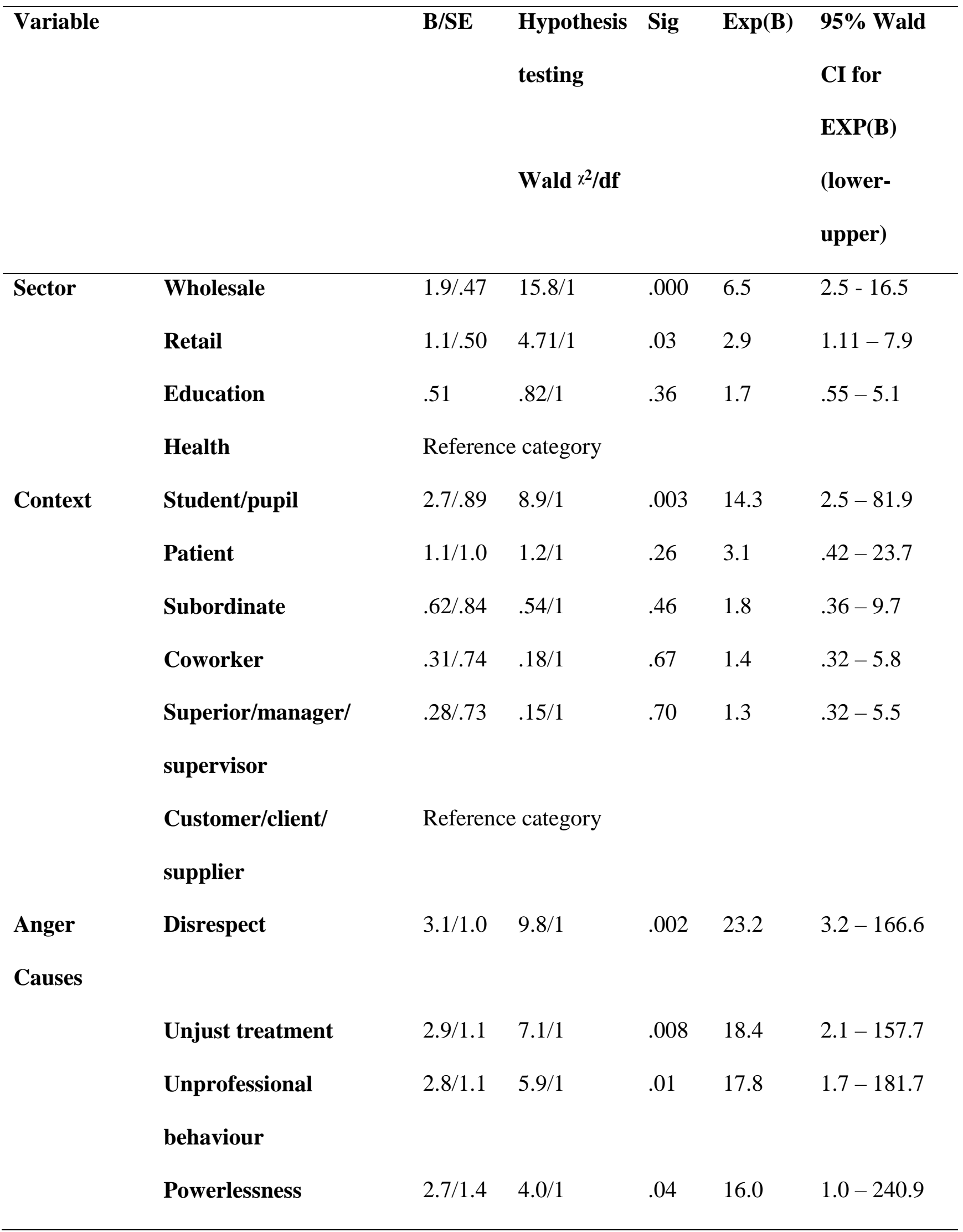




\begin{tabular}{|c|c|c|c|c|c|c|}
\hline & Humiliation/Jealousy & $2.6 / 1.1$ & $5.3 / 1$ & .02 & 13.0 & $1.5-115.9$ \\
\hline & Job incompetence & $2.28 / 1$ & $4.7 / 1$ & .03 & 9.8 & $1.2-77.5$ \\
\hline & & 0 & & & & \\
\hline & Lack of & $2.2 / 1.1$ & $3.6 / 1$ & .057 & 8.8 & $.94-82.3$ \\
\hline & support/recognition & & & & & \\
\hline & Repetitive problem & $1.9 / 1.1$ & $2.9 / 1$ & .08 & 6.9 & $.76-63.9$ \\
\hline & Mismanagement & $1.9 / 1.0$ & $3.2 / 1$ & .07 & 6.7 & $.83-54.5$ \\
\hline & Immoral behaviour & $1.8 / .98$ & $3.4 / 1$ & .065 & 6.1 & .89042 .1 \\
\hline & Lack of team work & $1.1 / 1.2$ & $.87 / 1$ & .35 & 3.1 & $.28-36.3$ \\
\hline & Poor communication & Referenc & e category & & & \\
\hline Already & Already stressed & $-.16 / .06$ & $7.9 / 1$ & .005 & .85 & $.76-.95$ \\
\hline stressed & & & & & & \\
\hline Job & Satisfaction with work & $.04 / .02$ & $6.4 / 1$ & .01 & 1.0 & $1.0-1.1$ \\
\hline satisfacti & & & & & & \\
\hline (JDI) & & & & & & \\
\hline & People & $-.07 / .02$ & $15.2 / 1$ & .000 & .93 & $.90-.96$ \\
\hline
\end{tabular}

